\title{
HYPONORMAL TRIGONOMETRIC TOEPLITZ OPERATORS
}

\author{
In SUng Hwang AND AN HyUn KIM
}

Abstract. We investigate hyponormal Toeplitz operators $T_{\phi}$ with trigonometric polynomial symbols $\phi$ via the Carathéodory-Schur Interpolation Problem. We present several formulae for computing the rank of the selfcommutator $\left[T_{\phi}^{*}, T_{\phi}\right]$ in the cases where $T_{\phi}$ is a hyponormal operator. In addition we consider the hyponormal extension problem of Toeplitz operators.

Mathematics subject classification (2010): Primary 47B20, 47B35, 47A20.

Keywords and phrases: Trigonometric Toeplitz operators, hyponormal operators.

\section{REFERENCES}

[1] A. Brown and P. R. Halmos, Algebraic properties of Toeplitz operators, J. Reine Angew. Math. $213(1963 / 1964), 89-102$.

[2] C. Cowen, Hyponormal and subnromal Toeplitz operators, Survey of Some Recent Results in Operator Theory, I (J. B. Conway and B. B. Morrel, eds.), Pitman Research Notes in Mathematics, Volume 171, Longman, 1988, pp. (155-167).

[3] C. Cowen, Hyponormality of Toeplitz operators, Proc. Amer. Math. Soc. 103 (1988), 809-812.

[4] R. E. Curto And W. Y. LeE, Joint hyponormality of Toeplitz pairs, Memoirs Amer. Math. Soc. 712, Amer. Math. Soc., Providence, 2001.

[5] R. E. Curto And W. Y. Lee, Reduced Cowen sets, New York J. Math. 7 (2001), 217-222.

[6] P. FAn, Remarks on hyponormal trigonometric Toeplitz operators, Rocky Mountain J. Math. 13 (1983), 489-493.

[7] D. R. FARenick And W. Y. LeE, Hyponormality and spectra of Toeplitz operators, Trans. Amer. Math. Soc. 348 (1996), 4153-4174.

[8] D. R. FARENICK AND W. Y. LEE, On hyponormal Toeplitz operators with polynomial and circulanttype symbols, Integral Equation and Operator Theory 29 (1997), 202-210.

[9] C. Foias AND A. Frazho, The Commutant Lifting Approach to Interpolation Problems, Operator Theory: Adv. Appl., vol 44, Birkhäuser-Verlag, Boston, 1990.

[10] J. B. GARnett, Bounded Analytic Functions, Academic Press, New York, 1981.

[11] I. Gohberg, S. Goldberg, And M. A. KaAshoek, Classes of linear operators, Vol II, Basel, Birkhauser, 1993.

[12] C. GU, A generalization of Cowen's characterization of hyponormal Toeplitz operators, J. Funct. Anal. 124 (1994), 135-148.

[13] C. Gu AND J. E. Shapiro, Kernels of Hankel operators and hyponormality of Toeplitz operators, Math. Ann. 319 (2001), 553-572.

[14] I. S. HwANG, I. H. Kim AND W. Y. LEE, Hyponormality of Toeplitz operators with polynomial symbols, Math. Ann. 313, 2 (1999), 247-261.

[15] I. S. Hwang, I. H. Kim AND W. Y. LeE, Hyponormality of Toeplitz operators with polynomial symbols: An extremal case, Math. Nach. 231 (2001), 25-38.

[16] I. S. HWANG AND W. Y. LEE, Hyponormality of trigonometric Toeplitz operators, Trans. Amer. Math. Soc. 354 (2002), 2461-2474.

[17] I. S. Hwang AND W. Y. LeE, Hyponormality of Toeplitz operators with rational symbols, Math. Ann. 335 (2006), 405-414.

[18] W. Y. LEE, Cowen sets for Toeplitz operators with finite rank selfcommutators, J. Operator Theory 54(2) (2005), 301-307. 
[19] T. NAKAZI AND K. TAKAHASHI, Hyponormal Toeplitz operators and extremal problems of Hardy spaces, Trans. Amer. Math. Soc. 338 (1993), 753-769.

[20] I. SCHUR, Über Potenzreihen die im Innern des Einheitskreises beschrānkt sind, J. Reine Angew. Math. 147 (1917), 205-232.

[21] S. TAKahashi, Extension of the theorems of Carathéodory-Toeplitz-Schur and Pick, Pacific J. Math. 138 (1989), 391-399.

[22] K. ZHU, Hyponormal Toeplitz operators with polynomial symbols, Integral Equations Operator Theory 21 (1996), 376-381. 